\title{
PREVALENCE AND RISK FACTORS ASSOCIATED WITH HEALTH DISORDERS AMONG HOSPITAL CLEANING WORKERS: A CROSS-SECTIONAL STUDY
}

\author{
By \\ Elbadry AS \\ Department of Community Medicine and Public Health, Faculty of Medicine, Menoufia University, \\ Menoufia, Egypt. \\ Elbadry AS:m_rezk9207@yahoo.com
}

\begin{abstract}
Introduction: Hospital cleaning workers are exposed to a variety of health hazards with little attention paid to them. Aim of work: to assess the prevalence and risk factors of work-related health disorders among hospital cleaning workers. Materials and methods: This cross-sectional study used a self-administered questionnaire to collect data on work-related risk factors and the occurrence of various health complaints among 5000 hospital cleaning workers (response rate 86.24\%). The frequency of health disorders among workers was estimated by using binary logistic regression analysis to detect the risk factors. Results: Health disorders among hospital cleaning workers in decreasing order of frequency was $24.7 \%$ respiratory symptoms, $18.3 \%$ skin symptoms, $16.7 \%$ combined respiratory and skin symptoms, $14.7 \%$ musculoskeletal symptoms, $11.1 \%$ combined skin and musculoskeletal symptoms, $8.4 \%$ psycho-social problems and $6.1 \%$ needle stick and sharp object injuries. Risk factors for health complaints included duration of working $>10$ years $(\mathrm{OR}=0.68, \mathrm{CI}=0.54-0.96)$, female gender $(\mathrm{OR}=1.78, \mathrm{CI}=1.58-3.88)$, working in the operating room $(\mathrm{OR}=1.56, \mathrm{CI}=1.26-2.82)$, working in surgical ward $(\mathrm{OR}=4.14, \mathrm{CI}=1.82-8.74)$, number of night shifts/month $>8$ $(\mathrm{OR}=1.78, \mathrm{CI}=1.24-4.86)$, absence of hard containers for needles $(\mathrm{OR}=1.96, \mathrm{CI}=1.52$ -2.78), absence of standard hospital policies ( $\mathrm{OR}=2.43, \mathrm{CI}=1.96-2.86)$, absence of primary medical examination $(\mathrm{OR}=1.68, \mathrm{CI}=1.12-3.24)$, absence of periodic medical examination $(\mathrm{OR}=0.18, \mathrm{CI}=0.03-0.24)$, absence of protective clothes except for gloves $(\mathrm{OR}=1.42, \mathrm{CI}=1.14-2.26)$, working hours $8-12$ hours per day $(\mathrm{OR}=2.12, \mathrm{CI}=1.42$ - 3.54) and working hours $>12$ hours/day ( $\mathrm{OR}=2.24, \mathrm{CI}=1.19-3.12)$. Conclusion: Health and safety of hospital cleaning workers has been inadequately provided which mandates the high need for health education, diagnostic and therapeutic interventions to this work group.
\end{abstract}

Key words: Hospital cleaning workers, Health disorders, Respiratory disorders, Skin disorders, Musculoskeletal disorders and Needle stick injuries. 


\section{Introduction}

Hospital cleaning workers perform a wide range of activities from light tasks as dusting, sweeping, and vacuuming to heavy duties as carrying heavy equipments and exposure to toxic cleaning solutions (Zock, 2005 and Magnano et al, 2009). The use of specific cleaning products at work as hydrochloric acid and detergents were associated with lower respiratory tract symptoms among women with current asthma in a previous study (Vizcaya et al, 2015). Among 667 health care workers and 124 cleaning and kitchen employees, irritant contact dermatitis was the most frequent single diagnosis in both groups with nearly $80 \%$ of the employees had skin lesions and 27\% had severe dermatosis (Weisshaar et al, 2007). A population of 99 women working in hospital cleaning activities in Italy participated in a study to define the risk assessment for cumulative trauma diseases (CTD), confirmed that carpal tunnel syndrome seems to be a disease related to cleaning workers although their risk assessment was negative for CTD (di Carlo et al, 2003).

\section{Aim of work}

To assess the prevalence and risk factors of work-related health disorders among hospital cleaning workers

\section{Materials and methods}

- Study design: It is a cross sectional study.

\section{- Place and duration of the study:} The study was done at 13 tertiary hospitals within Menoufia governorate included Menoufia University hospital, Shibin El-Kom Teaching hospital and 11 central hospitals; during the period from April 2017 to the end of August 2018.

- Study sample: A total of 5000 hospital cleaning workers were enrolled in the study after thorough explanations of the study objectives through personal interviews with the chiefs of the corresponding hospitals.

- Study methods: Out of 5000 predesigned questionnaire forms were distributed to all hospital cleaning workers and collected after completion; 4312 forms were returned with a response rate of $86.24 \%$. The pre-designed questionnaire included three sections; section one included questions about demographic characteristics as age and gender, section two included current and past occupational history with emphasis on primary and periodic medical examinations, availability and use of 
protective clothes other than gloves, availability of appropriate hard containers to collect used needles, duration of employment, place of work, working hours per day and number of night shifts per month, and finally section three included questions about health hazards and symptoms in the respiratory, skin, musculoskeletal systems, occurrence of needle stick injuries and psychosocial problems with their frequency over the past three months with corresponding search for medical advice, administration of specific drugs or admission to hospitals.

\section{Consent}

Written informed consents were signed by all participants before being enrolled into the study.

\section{Ethical approval}

The Medical Ethics Committee at Menoufia Faculty of Medicine approved the study protocol before starting the study.

\section{Data management}

Data were analyzed using IBM SPSS version 22 (SPSS Inc., Chicago, IL). Chi-square test was used to examine the relation between qualitative variables. For quantitative data, comparison between two groups was done using student t-test. This study employed logistic regression analysis to assess the factors associated with health disorders among the studied health care workers. The results were expressed as odds ratios (OR) with $95 \%$ confidence intervals $(\mathrm{CI})$. The value $\mathrm{p} \leq 0.05$ was treated as statistically significant.

\section{Results}

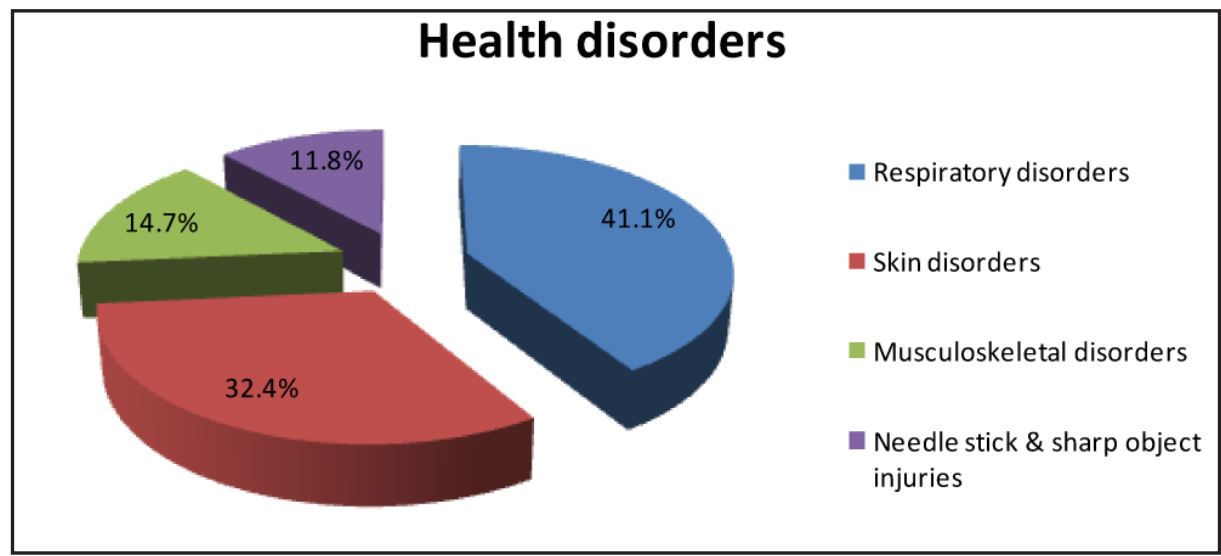

Figure (1): Prevalence of health disorders among hospital cleaning workers. 
Figure 1 showed the prevalence of health disorders among hospital cleaning workers which was in decreasing order of frequency; $41.1 \%$ respiratory symptoms, $32.4 \%$ skin symptoms, $14.7 \%$ musculoskeletal symptoms and $11.8 \%$ needle stick and sharp object injuries.

Table (1): Risk factors for health disorders among hospital cleaning workers in relation to the number of complaints per month over the last 3 months $\left(\mathrm{N}_{\mathrm{o}}=4312\right)$ :

\begin{tabular}{|c|c|c|c|c|}
\hline \multirow[b]{2}{*}{ Risk factors } & \multicolumn{2}{|c|}{ Number of complaints per month } & \multirow[b]{2}{*}{$\begin{array}{c}\text { Test of } \\
\text { significance }\end{array}$} & \multirow[b]{2}{*}{ p value } \\
\hline & $\begin{array}{c}<3 \text { times } \\
(\mathrm{No}=2142)\end{array}$ & $\begin{array}{l}\geq 3 \text { times } \\
(\mathrm{No}=2170)\end{array}$ & & \\
\hline $\begin{array}{l}\text { Age (years) } \\
\text { Mean } \pm \text { SD }\end{array}$ & $37.18 \pm 8.66$ & $36.98 \pm 8.78$ & $\mathrm{t}=0.75$ & 0.45 \\
\hline $\begin{array}{l}\text { Duration of work ( years) } \\
<10 \\
>10\end{array}$ & $\begin{array}{c}846(39.5 \%) \\
1296(60.5 \%)\end{array}$ & $\begin{array}{c}1222(56.3 \%) \\
948(43.5 \%)\end{array}$ & $\chi^{2}=121.4$ & $<0.001 * *$ \\
\hline $\begin{array}{l}\text { Gender } \\
\text { Male } \\
\text { Female }\end{array}$ & $\begin{array}{l}1068(49.9 \%) \\
1074(50.1 \%)\end{array}$ & $\begin{array}{c}934(43.0 \%) \\
1236(57.0 \%)\end{array}$ & $\chi^{2}=19.88$ & $<0.001 * *$ \\
\hline $\begin{array}{l}\text { Place } \\
\text { Operative room } \\
\text { Internal wards }\end{array}$ & $\begin{array}{c}1382(64.5 \%) \\
760(35.5 \%)\end{array}$ & $\begin{array}{l}1008(46.5) \\
1162(53.5)\end{array}$ & $\chi^{2}=141.7$ & $<0.001 * *$ \\
\hline $\begin{array}{l}\text { Hard containers } \\
\text { Present } \\
\text { Absent }\end{array}$ & $\begin{array}{c}1348(62.9) \\
794(37.1)\end{array}$ & $\begin{array}{c}666(30.7) \\
1504(69.3)\end{array}$ & $\chi^{2}=484.8$ & $<0.001 * *$ \\
\hline $\begin{array}{l}\text { Number of night shifts/month: } \\
\leq 8 \\
>8\end{array}$ & $\begin{array}{l}1086(50.7 \%) \\
1056(49.3 \%)\end{array}$ & $\begin{array}{c}928(42.8 \%) \\
1242(57.2 \%)\end{array}$ & $\chi^{2}=26.9$ & $<0.001 * *$ \\
\hline $\begin{array}{l}\text { Ward } \\
\text { Medical } \\
\text { Surgical }\end{array}$ & $\begin{array}{c}1232(57.5 \%) \\
42.5 \%)) 910\end{array}$ & $\begin{array}{c}910(41.9 \%) \\
1260(58.1 \%)\end{array}$ & $\chi^{2}=104.1$ & $<0.001 * *$ \\
\hline $\begin{array}{l}\text { Hospital policies } \\
\text { Present } \\
\text { Absent }\end{array}$ & $\begin{array}{c}52.5 \%)) 1124 \\
1018(47.5 \%)\end{array}$ & $\begin{array}{l}1014(46.7 \%) \\
1156(53.3 \%)\end{array}$ & $\chi^{2}=14.01$ & $<0.001 * *$ \\
\hline $\begin{array}{l}\text { Primary examination } \\
\text { Present } \\
\text { Absent }\end{array}$ & $\begin{array}{c}1146(53.5 \%) \\
996(46.5 \%)\end{array}$ & $\begin{array}{l}1050(48.4 \%) \\
1120(51.6 \%)\end{array}$ & $\chi^{2}=11.08$ & $<0.001 * *$ \\
\hline $\begin{array}{l}\text { Periodic examinations } \\
\text { Yes } \\
\text { NO }\end{array}$ & $\begin{array}{c}768(35.9 \%) \\
1374(64.1 \%)\end{array}$ & $\begin{array}{c}1334(61.5 \%) \\
836(38.5 \%)\end{array}$ & $\chi^{2}=282.18$ & $<0.001 * *$ \\
\hline $\begin{array}{l}\text { Protective clothes } \\
\text { Yes } \\
\text { NO }\end{array}$ & $\begin{array}{l}1120(52.3 \%) \\
1022(47.7 \%)\end{array}$ & $\begin{array}{c}994(45.8 \%) \\
1176(54.2 \%)\end{array}$ & $\chi^{2}=17.86$ & $<0.001 * *$ \\
\hline $\begin{array}{l}\text { Working hours } \\
\leq 8 \\
>8-12 \\
>12\end{array}$ & $\begin{array}{l}860(40.1 \%) \\
796(37.2 \%) \\
486(22.7 \%)\end{array}$ & $\begin{array}{l}492(22.7 \%) \\
964(44.4 \%) \\
714(32.9 \%) \\
\end{array}$ & $\chi^{2}=159.35$ & $<0.001 * *$ \\
\hline
\end{tabular}

**: Highly statistically significant 
Table 1 showed that there was a statistically significant difference between workers who were complaining less than 3 times per month and those with more than 3 times per month as regard duration of work $>10$ years, female gender, working in the operating room, absence of hard containers for needles, working in emergency ward, increased number of night shifts $>8$, absence of standard hospital policies, increased working hours per day $>8$ hours, lack of protective clothes, absence of pre-employment examination and periodic medical examination risk factors.

Table (2): Logistic regression analysis to detect risk factors associated health disorders among cleaning workers.

\begin{tabular}{|c|c|c|c|c|}
\hline Risk factors & Beta $(\beta)$ & $\begin{array}{l}\text { Odds ratio } \\
\quad(\text { OR) }\end{array}$ & p-value & $95 \%$ CI \\
\hline $\begin{array}{l}\text { Duration of work } \\
<10 \text { year (reference) } \\
>10 \text { year }\end{array}$ & -0.947 & 0.68 & $0.01 *$ & $0.54-0.96$ \\
\hline $\begin{array}{l}\text { Gender } \\
\text { Male (reference) } \\
\text { Female }\end{array}$ & 0.641 & 1.78 & $0.03 *$ & $1.58-3.88$ \\
\hline $\begin{array}{l}\text { Place of working } \\
\text { OR (reference) } \\
\text { Internal ward }\end{array}$ & 0.198 & 1.56 & $0.004 *$ & $1.26-2.82$ \\
\hline $\begin{array}{l}\text { Ward } \\
\text { Medical (reference) } \\
\text { Surgical }\end{array}$ & 1.38 & 4.14 & $0.001 * \dagger$ & $1.82-8.74$ \\
\hline $\begin{array}{l}\text { Number of night shifts } \\
\leq 8 \text { (reference) } \\
>8\end{array}$ & 0.288 & 1.78 & $0.03 *$ & $1.24-4.86$ \\
\hline $\begin{array}{l}\text { Hard containers } \\
\text { Present (reference) } \\
\text { Absent }\end{array}$ & 0.678 & 1.96 & $0.007 *$ & $1.52-2.78$ \\
\hline $\begin{array}{l}\text { Hospital policies } \\
\text { Present (reference) } \\
\text { Absent }\end{array}$ & 0.082 & 2.43 & $0.02 *$ & $1.96-2.86$ \\
\hline $\begin{array}{l}\text { Primary examination } \\
\text { Present (reference) } \\
\text { Absent }\end{array}$ & 0.154 & 1.68 & $0.01 *$ & $1.12-3.24$ \\
\hline $\begin{array}{l}\text { Periodic examination } \\
\text { Yes (reference) } \\
\text { NO }\end{array}$ & $3.38 t$ & 0.18 & $0.001 * *$ & $0.03-0.24$ \\
\hline
\end{tabular}




\section{Protective clothes}

Yes (reference)

NO

0.332

1.42

$0.04 *$

$1.14-2.26$

Working hours

$\leq 8$ (reference)

$>8-12$

$>12$

0.74

0.76

2.12

$0.006 *$

$\begin{array}{lll}2.24 & \mathbf{0 . 0 0 1} * * & 1.19-3.12\end{array}$

$1.42-3.54$

$†$ Hosmer and Lemeshow Test Chi-square $=91.66(\mathrm{p}<0.001)$;

$\$$ Omnibus Tests of Model Coefficients Chi-square $=86.97(\mathrm{p}<0.001)$.

The model explained $70.4 \%$ of the variency and correctly classified $80.1 \%$.

OR: Operating room, $\quad *$ : Statistically significant, $\quad * *$ : Highly statistically significant

Logistic regression analysis revealed that duration of work $>10$ years, female gender, working in the operating room, working in surgical ward, number of night shifts/month $>8$, absence of hard containers for needles , absence of standard hospital policies , absence of primary medical examination , absence of periodic medical examination, absence of protective clothes except for gloves , working hours 8-12 hours per day and working hours $>12$ hours were considered as risk factors associated with health disorders among cleaning workers as shown in Table 2.

\section{Discussion}

A predesigned questionnaire was distributed to 5000 professional cleaning workers and collected after completion with 4312 forms were returned (response rate 86.24\%). Our study revealed that health disorders among hospital cleaning workers in decreasing order of frequency was $41.1 \%$ respiratory symptoms, $32.4 \%$ skin symptoms, $14.7 \%$ musculoskeletal symptoms and $11.8 \%$ needle stick and sharp object injuries (Figure 1).

Our work showed that $41.4 \%$ of the studied group was complaining of respiratory symptoms (Figure 1) which is higher than the figure declared recently by Hawley et al, 2017 who conducted their study on 50 hospital cleaning staff with $34 \%$ of workers reported lower respiratory symptoms over the past 12 months. This discrepancy may be related to the lower rate of availability and usage of personal protective equipments in our study.

In a recent study comprised 50 professional cleaning women, workrelated asthma was diagnosed in $46 \%$ of 
symptomatic cleaners, of whom 15 were considered as having work-exacerbated asthma while 8 as having occupational asthma following thorough history taking, skin prick tests, serum specific IgE antibodies, and specific inhalant challenge test (Lipińska-Ojrzanowska et al, 2017).

The increased risk of asthma among the studied group has been shown to be related to the duration of employment which is confirmed in the current study as working for more than 10 years (Table 2) and also due to the lack of use of protective equipments.

Our study showed that $32.4 \%$ of the studied group were complaining of skin symptoms (Figure 1) which is higher than the results reported by Mirabelli et al, 2012 who examined 818 professional cleaning workers in Spain , and detected that hand dermatitis was present in $28 \%$ of their studied sample and was associated with the use of hydrochloric acid. The higher percentage among our study group may be due to the shortage in the use of protective equipments.

One thousand five hundred and four patients (1020 women and 484 men) were included in a register-based study including workers with occupational contact dermatitis in Denmark in 2010 revealed that irritant contact dermatitis was diagnosed in $70 \%$ of all cases with $68 \%$ of these were caused by wet work. Forty-six percent of all patients were employed either in the healthcare sector, in cleaning, or as kitchen workers (Carøe et al, 2014).

The current study showed that $14.7 \%$ of the studied group had musculoskeletal complaints (Figure 1). Cleaning workers who were involved in repetitive manual tasks were more prone for work-related upper-limb musculoskeletal injury (Bell et al, 2012).

A total of 145 musculoskeletal injuries and cuts were identified among hospital cleaners, with an annual incidence rate of 32.1 per 100 personyears in two health care facilities in the Canadian province of British Columbia. Musculoskeletal injury was more common in females and those working in acute care facility. Cleaners with $>10$ years of experience were at significantly lower risk for all injuries and irritation incidents (Alamgir et al, 2008).

In a previous cross sectional study on 624 workers, low back pain was associated with longer working hours, flexion and trunk rotation, psychosocial demands and working directly in 
collection. Many workers develop their activity at the presence of pain to keep their job (Pataro et al, 2014).

In our study, female workers have higher rate of complaints than men (the difference was statistically-significant) (Table 1). Female workers were more exposed to cleaning products with a higher frequency of work-related health disorders than men (Lee et al, 2014).

In a French national study included 3738 cases with occupational allergic contact dermatitis, $52 \%$ of the cleaning staff were women (Bensefa-Colas et al, 2014) which is similar to our study as $2310(53.57 \%)$ of the hospital cleaning workers were females (Table 1).

Our study revealed that, working in the operating room, working in surgical ward and absence of protective clothes except for gloves were independent risk factors for health problems (Table 2). In a previous pilot study included 183 cleaning workers, data on health disorders and occupational factors were collected by personal interviews or selfadministered questionnaires. Chemicalrelated symptoms were more common among workers who performed patient area cleaning (44\%) and except for gloves; regular use of personal protective equipments was infrequent
(Lee et al, 2014).

In the current study, absence of hard containers for used needles and absence of standard hospital policies for disinfection were independent risk factors for health problems (Table 2).In a study done by Beghdadli et al, 2009 , 108 exposures to blood were reported by 70 women and 38 men in which needle stick injuries represented $81 \%$ of cases. Cleaning staff and hygiene workers are at high risk of blood contamination and more than one-third of injuries occurred because of mismanagement of hospital waste products, where needles were not disposed appropriately in hard containers.

\section{Limitations of the study:}

Self reported questionnaire over the past three months may be the victim from recall bias as well as noninclusion of the private sector to assess the risk of exposure to health hazards; both elements constitute unintended limitation of this study.

\section{Conclusion and recommendations}

Hospital cleaning workers are at high risk for respiratory, skin, musculoskeletal disorders and needle stick injury, either alone or in combination secondary to their 
occupational exposure to hazardous materials.

Health and safety of hospital cleaning workers has been inadequately provided which mandates the high need for health education, diagnostic and therapeutic interventions to this work group.

Future research should focus on the type of educational training considering the perceived benefits and disadvantages while developing plans to decrease health hazards among hospital cleaning workers.

\section{Conflicts of interest}

None declared

\section{Acknowledgement}

The author would like to thank the responders for their time to provide valuable information.

\section{References}

1. 1.Alamgir H and Yu S (2008): Epidemiology of occupational injury among cleaners in the healthcare sector. Occup Med (Lond); 58(6):393-9.

2. 2.Beghdadli B, Ghomari O, Taleb M, Belhaj $\mathrm{Z}$, Belabed A, et al.(2009): Personnel at risk for occupational blood exposure in a university hospital in West Algeria. Sante Publique; 21(3):253-61.

3. 3. Bell AF and Steele JR (2012): Risk of musculoskeletal injury among cleaners during vacuuming. Ergonomics; 55(2):237-47.
4. 4.Bensefa-Colas L, Telle-Lamberton M, Paris C, Faye S, Stocks SJ, et al.(2014): Occupational allergic contact dermatitis and major allergens in France: temporal trends for the period 20012010. Br J Dermatol; 171(6):1375-85.

5. 5.Carøe TK, Ebbehøj N and Agner T(2014): A survey of exposures related to recognized occupational contact dermatitis in Denmark in 2010. Contact Dermatitis; 70(1):56-62.

6. 6.di Carlo D, Tangredi G, Giudici M and Papini K (2003): Carpal tunnel syndrome and cleaning work: a binomial that should not be overlooked. G Ital Med Lav Ergon; 25 Suppl(3):247-8.

7. 7.Lee SJ, Nam B, Harrison $\mathrm{R}$ and Hong $\mathrm{O}$ (2014): Acute symptoms associated with chemical exposures and safe work practices among hospital and campus cleaning workers: a pilot study. Am J Ind Med; 57(11):1216-26.

8. 8.Lipińska-Ojrzanowska A, Wiszniewska M, Świerczyńska-Machura D, Wittczak T, Nowakowska-Świrta E, et al. (2014): Workrelated respiratory symptoms among health centres cleaners: a cross-sectional study. Int J Occup Med Environ Health; 27(3):460-6.

9. 9. Lipinska-Ojrzanowska AA, Wiszniewska M and Walusiak-Skorupa JM (2017): Workrelated asthma among professional cleaning women. Arch Environ Occup Health; 72(1):5360.

10. 10. Magnano M, Silvani S, Vincenzi C, Nino $\mathrm{M}$ and Tosti A (2009): Contact allergens and irritants in household washing and cleaning products. Contact Dermatitis; 61:337-41.

11. 11.Mirabelli MC, Vizcaya D, Martí Margarit A, Antó JM, Arjona L, Barreiro E, et al. (2012): Occupational risk factors for hand dermatitis among professional cleaners in Spain. Contact Dermatitis; 66(4):188-96.

12. 12.Pataro SM and Fernandes RC (2014): Heavy physical work and low back pain: the reality in urban cleaning. Rev Bras Epidemiol; 17(1):1730.

13. 13.Vizcaya D, Mirabelli MC, Gimeno D, Antó JM, Delclos GL,et al. (2015): Cleaning products 
and short-term respiratory effects among female cleaners with asthma. Occup Environ Med; 72(11):757-63.

14. 14.Weisshaar E, Radulescu M, Soder S, Apfelbacher CJ, Bock M, et al. (2007): Secondary individual prevention of occupational skin diseases in health care workers, cleaners and kitchen employees: aims, experiences and descriptive results. Int Arch Occup Environ Health; 80(6):477-84.

15. 15. Zock JP (2005): World at work: cleaners. Occup Environ Med; 62:581-4. 